\title{
Quantitative Detection of Reverse Transcriptase-PCR Products by Means of a Novel and Sensitive DNA Stain
}

\author{
Christian Schneeberger, ${ }^{1}$ Paul Speiser, ${ }^{1}$ Fritz Kury, ${ }^{2}$ and Robert Zeillinger ${ }^{1}$
}

${ }^{1}$ Department of Obstetrics and Gynecology, Molecular Oncology Division, University of Vienna; ${ }^{2}$ ViennaLab Labordiagnostika GmbH., Vienna, Austria

We constructed a plasmid for the in vitro synthesis of a competitor RNA for use as an internal exogenous control during reverse transcriptasePCR (RT-PCR) detection of epidermal growth factor receptor (EGFR) expression. The competitor RNA harbors a 32-base deletion compared with wild-type EGFR mRNA and generates a PCR product that is easily distinguished from the wild-type PCR product by agarose gel electrophoresis. We encountered the problem of heteroduplex formation during later stages of PCR, which could be solved by decreasing the PCR cycle number. This was accompanied by a significant loss of sensitivity. Sensitivity could be restored by using a novel and extremely sensitive DNA stain (SYBR Green I) instead of ethidium bromide. ompetitive reverse transcriptasepolymerase chain reaction (competitive RT-PCR) is being used increasingly for determination and quantification of gene expression, particulary when test sample size is limited and high sensitiv- ity is required. ${ }^{(1,2)}$ The use of internal control templates in competitive RTPCR is necessary to ensure that the reverse transcription and the PCR have functioned as expected and to generate a standard curve from which the concen-

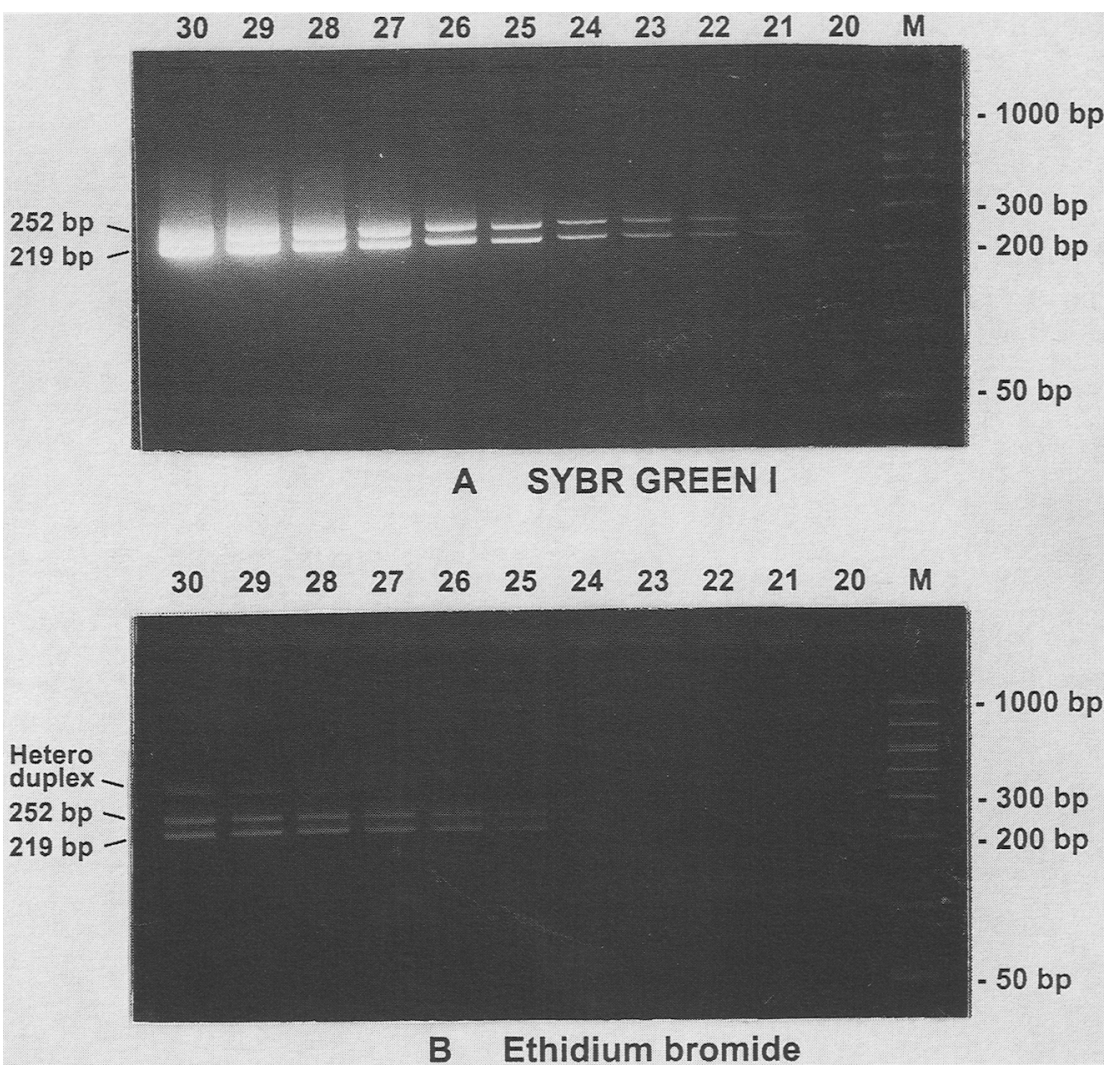

FIGURE 1 SYBR Green I- $(A)$ and ethidium bromide-stained $(B)$ agarose gel of competitive RTPCR products $(12 \mu \mathrm{l}$ PCR product). $(A)$ The extreme sensitivity of this DNA stain; $(B)$ the effect of decreasing PCR cycle numbers on the formation of heteroduplexes. The total RNA (500 ng) extracted from a breast cancer sample, was reverse transcribed and amplified in the presence of 50 pg of EGFR-competitor RNA. Lanes 20-30 correspond to 20-30 PCR cycles; (lane M): BioMarker Low (Bioventures, Inc., Murfreesboro, TN). 
tration of the target sequence in the test sample can be deduced. ${ }^{(3-5)}$ Internal controls can be exogenous mRNA added to the cDNA synthesis reaction or endogenous mRNA. Exogenous internal standards that share the same primer annealing sequences with the target allow calculation of the absolute amount of target mRNA. ${ }^{(6)}$ However, two conditions must be met to use competitive RT-PCR: (1) The quantity of the competitor RNA (or DNA) must be known, and (2) the amplification efficiency of the competitor and target must be identical. This occurs often if the standard and the target possess the same primer binding sites.

To test these conditions, we constructed a plasmid (pEGFR-219) for the in vitro synthesis of a competitor RNA for use as an internal exogenous control during RT-PCR detection of epidermal growth factor receptor (EGFR) expression. The competitor RNA harbors a 32base deletion compared with wild-type EGFR mRNA. Different amounts of competitor RNA and fixed amounts of total cellular RNA are reverse transcribed simultaneously in the same reaction tube, which allows the generation of a standard curve. Upon amplification of the synthesized $\mathrm{cDNAs}$ by using the same primer pair, the competitor RNA generates a PCR product that is easily distinguished from the wild-type PCR product by agarose gel electrophoresis without further manipulation.

During the course of experiments designed to optimize and establish the competitive RT-PCR method, we encountered formation of heteroduplexes during later stages of PCR. Heteroduplexes, identified by reduced electrophoretic mobility, were generated by cross-hybridization of competitor and wild-type sequences. In later amplification cycles, when the concentration of products is high, the probability of such a recombination event is increased. In particular, heteroduplexes formed in the last amplification cycle are not denatured and, therefore, form a significant portion of the final product profile. ${ }^{(3,7-9)}$ We noticed that heteroduplex formation often interfered with the attainment of accurate quantitative results. The problem of heteroduplex formation can be resolved by decreasing the PCR cycle number from 30 to 25 , which is accompanied by a significant loss of sensitivity. Sensitivity can be restored by using

\section{Relative amount of heteroduplexes vs. cycle number}

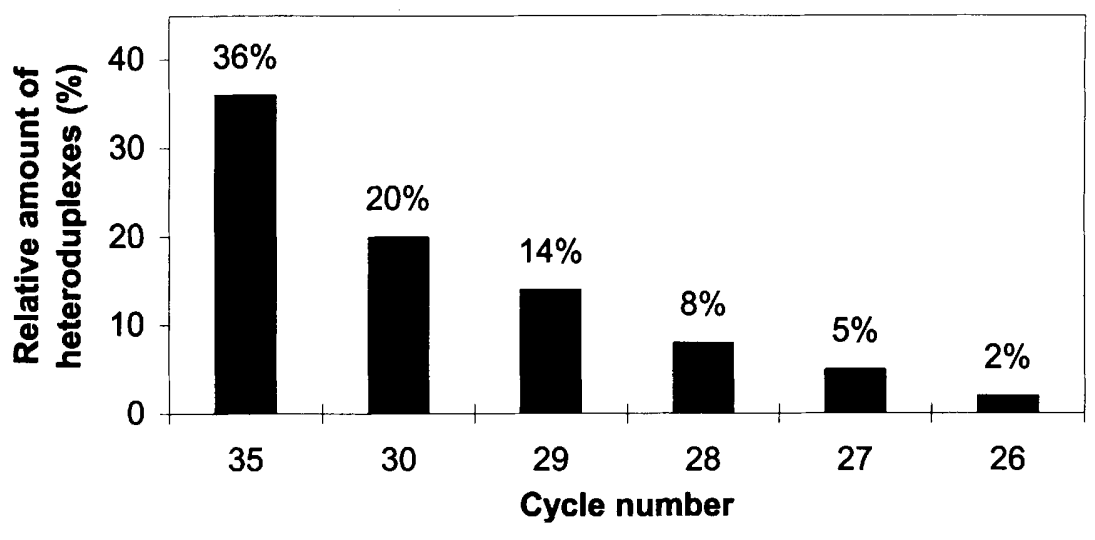

FIGURE 2 Relationship among total lane intensities (252-bp band + 219-bp band + heteroduplex band) and heteroduplex intensities. Quantitation was performed by densitometric scanning of the gels shown in Fig. 1B (lanes 26-30) and Fig. 3B (lane 2), using a CCD Video Camera Imaging System (Vilber Lourmat, Marne la Vallee, France). a novel and extremely sensitive DNA stain (SYBR Green I; Molecular Probes, Inc., Eugene, OR) instead of ethidium bromide. The remarkable sensitivity of SYBR Green I can be attributed to a combination of unique dye characteristics. SYBR Green I exhibits exceptional affinity for DNA and a large fluorescence en hancement upon DNA binding - at least one order of magnitude greater than that of ethidium bromide. Also, the fluorescence quantum yield of the DNA/SYBR Green I complex is more than five times greater than that of DNA/ethidium bromide (Product information, Molecular Probes, Inc.).

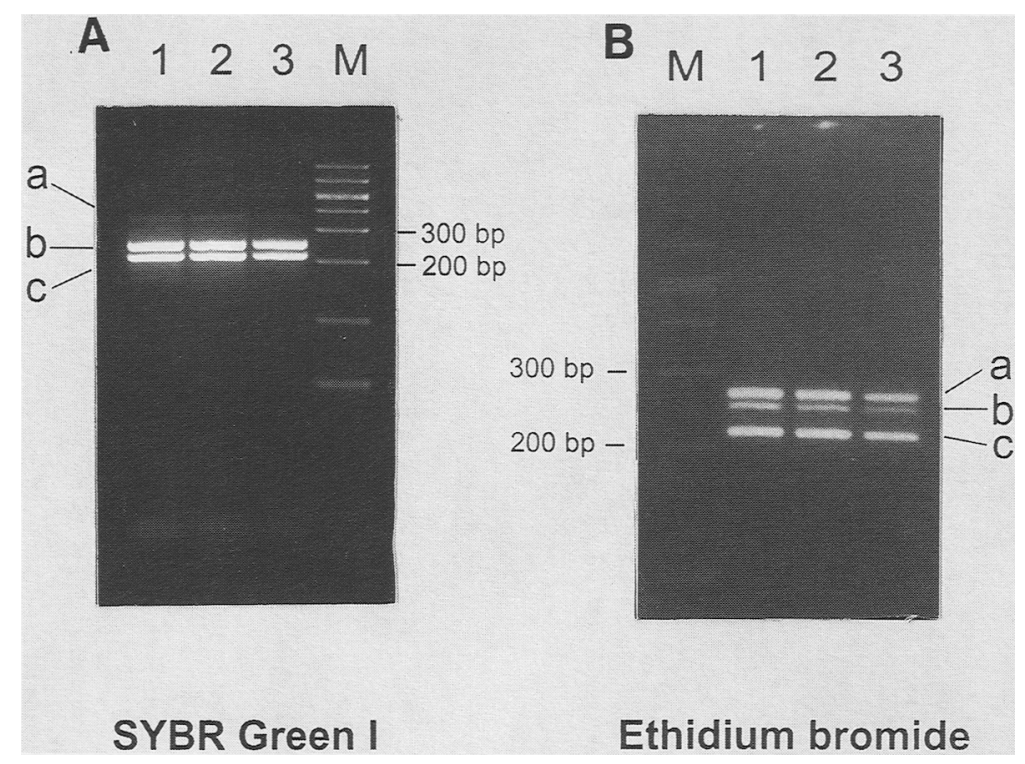

FIGURE 3 SYBR Green I- $(A)$ and ethidium bromide-stained $(B)$ agarose gels of a competitive RT-PCR experiment (35 PCR cycles). Staining was done by adding the dyes to the agarose solution prior to pouring the gel. (a) Heteroduplex band; (b) 252-bp band; (c) 219-bp band). (Lane 1) 15- $\mu$ l PCR product; (lane 2) 10- $\mu$ l PCR product; (lane 3) 5- $\mu$ l PCR product; (lane M) BioMarker Low. 


\section{MATERIALS AND METHODS \\ RNA Extraction and Reverse Transcription}

Total RNA was extracted from cell lines and tumor tissue by isopycnic centrifugation as described. ${ }^{(10)}$ cDNA was synthesized in $50 \mu \mathrm{l}$ total volume containing the commercially available Random Primed Reverse Transcription Reaction Mix (ViennaLab, Vienna, Austria), 40 units of RNasin (Promega Madison, WI), 100 units of Mu-MLV reverse transcriptase (ViennaLab), and $30 \mu \mathrm{l}$ of template RNA (competitor RNA and wildtype RNA). Reactions were incubated at room temperature for $10 \mathrm{~min}$ followed by $50 \mathrm{~min}$ at $37^{\circ} \mathrm{C}$ and $5 \mathrm{~min}$ at $95^{\circ} \mathrm{C}$.

\section{Construction of PEGFR-219}

A 252 bp-EGFR-cDNA fragment was am- plified using a tumor-derived cDNA as template, primer EGFR-5' (position 1152-1170 of the EGFR cDNA sequence, ${ }^{(11)}$ and primer EGFR-3' (position 1386-1404 of the EGFR cDNA sequence. ${ }^{(1)}$ MseI (Boehringer Mannheim, Mannheim, Germany) digestion of the amplified sequence yielded fragments of 150,69, and $33 \mathrm{bp}$, which were separated by agarose gel electrophoresis and isolated using an agarose-digesting enzyme (Gelase; Epicentre Technologies, Madison, WI). Fragments of 150 and 69 bp were ligated using T4 DNA ligase (Boehringer Mannheim). The ligated product was reamplified using primers EGFR-5' and EGFR-3' and purified by agarose gel electrophoresis. The resulting 219-bp fragment was cloned into plasmid pCR II, according to the manufacturer's instructions (TA Cloning System; Invitrogen, San Diego, CA) and

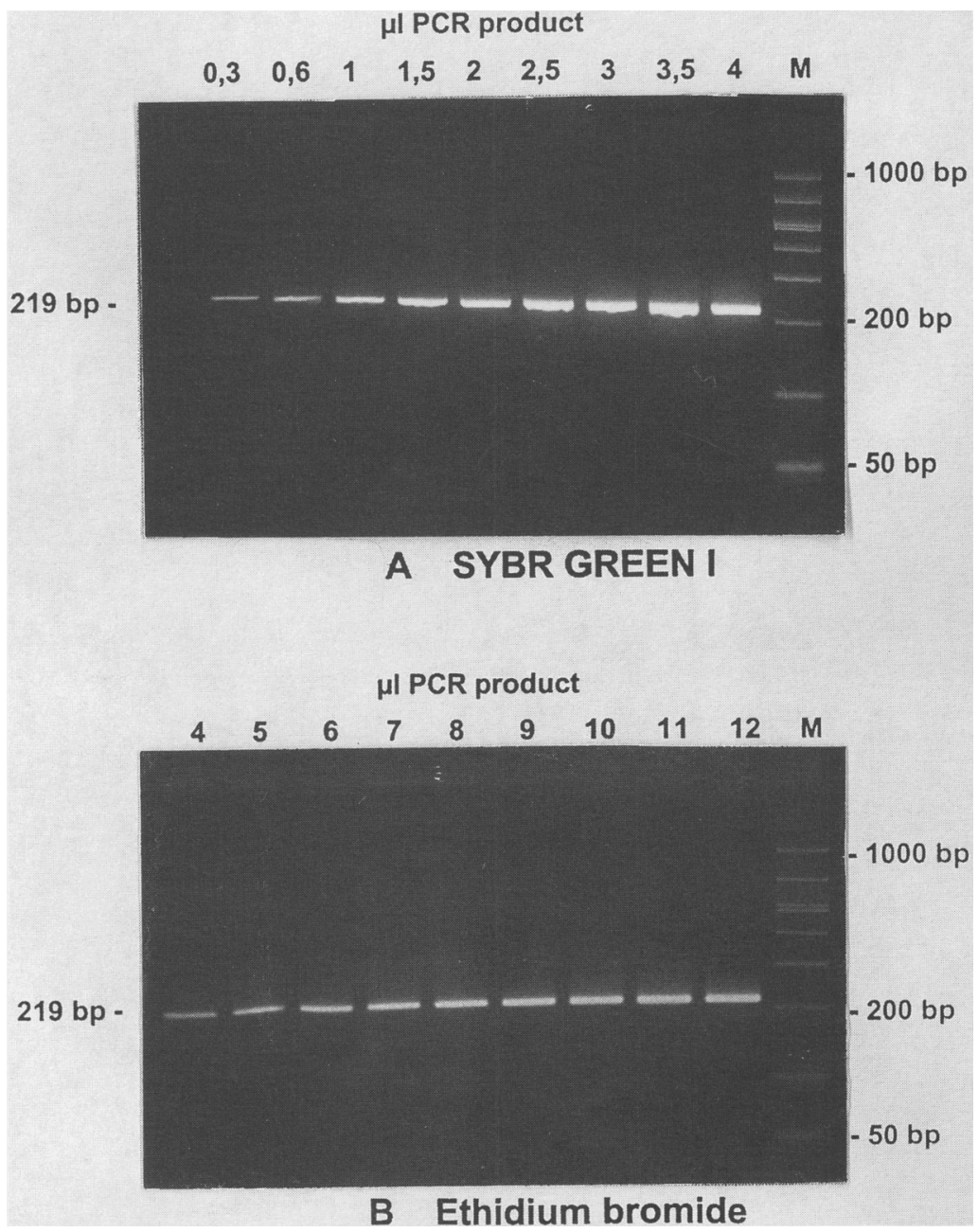

FIGURE 4 Dilution series of a 219-bp PCR fragment, stained either with SYBR Green I $(A)$ or ethidium bromide $(B) .100 \mathrm{fg}$ competitor RNA $\left(\sim 5 \times 10^{5} /\right.$ molecules $)$ was reverse transcribed, $1 / 50$ of the cDNA was used for PCR (30 cycles). $1 \mu$ l PCR product corresponds to $\sim 2000$ molecules of competitor RNA. (Lane M) BioMarker Low.

named pEGFR-219. pEGFR-219 was used to transform Escherichia coli INVaF' (Invitrogen). Positive clones were selected by their blue/white color and checked for the presence of the expected deletion mutant by PCR using primers EGFR-5' and EGFR-3'.

\section{In Vitro RNA Synthesis}

Plasmid pEGFR-219 was purified by using a Qiagen Plasmid Kit (Qiagen, Inc., Studio City, CA) and linearized with BamHI (Boehringer Mannheim). Competitor RNA was synthesized by using the AmpliScribe T7 Transcription kit from Epicentre Technologies. Template DNA was removed by digestion with RNasefree DNase (Epicentre Technologies). In vitro-synthesized RNA was recovered by ethanol precipitation, controlled and purified by polyacrylamide gel electrophoresis ( $5 \%$ acrylamide, $8 \mathrm{~m}$ urea), and quantified by measuring the absorbance at $260 \mathrm{~nm}$.

\section{DNA Amplification}

PCR was performed on a Perkin-Elmer GeneAmp PCR System 9600 and carried out in a total volume of $50 \mu \mathrm{l}$ containing 1-2 $\mu$ l of cDNA template, 20 pmoles of primer EGFR-5' (5'-CGTCCGCAAGTGTAAGAA-3', ViennaLab), 20 pmoles of primer EGFR-3' (5'-AGCAAAAACCCTGTGATT-3'; ViennaLab), $250 \mu \mathrm{M}$ dNTPs, 10 mM Tris- $\mathrm{HCl}$ (pH 9.0), $50 \mathrm{~mm} \mathrm{KCl,} \mathrm{0.01 \%}$ (wt/vol) gelatin, $1.5 \mathrm{~mm} \mathrm{MgCl}, 0.1 \%$ Triton $\mathrm{X}-100$, and 0.2 unit Hi-Taq DNA Polymerase (ViennaLab). Amplification cycles were as follows: $94^{\circ} \mathrm{C}$ for $30 \mathrm{sec}$, $50^{\circ} \mathrm{C}$ for $30 \mathrm{sec}$, and $72^{\circ} \mathrm{C}$ for $45 \mathrm{sec}$. The 20-30 amplification cycles were preceded by a primary denaturation step $\left(94^{\circ} \mathrm{C}\right.$ for $\left.1 \mathrm{~min}\right)$.

\section{PCR Product Analysis}

PCR products were separated by agarose gel electrophoresis (3\% NuSieve agarose/ 1\% GTG agarose; FMC BioProducts, Rockland, ME). All agarose gels used for comparison of staining efficiency were of the same dimension and volume. Electrophoresis was performed at 10 $\mathrm{V} / \mathrm{cm}$ for $30 \mathrm{~min}$. Staining was done either by incubating the gel after electrophoresis in staining solution $[1: 10,000$ dilution of the SYBR Green I stock reagent in $1 \times$ TAE (40 mM Tris-acetate, 1 mM EDTA) or $5 \mu \mathrm{g}$ ethidium bromide $/ \mathrm{ml}$ 

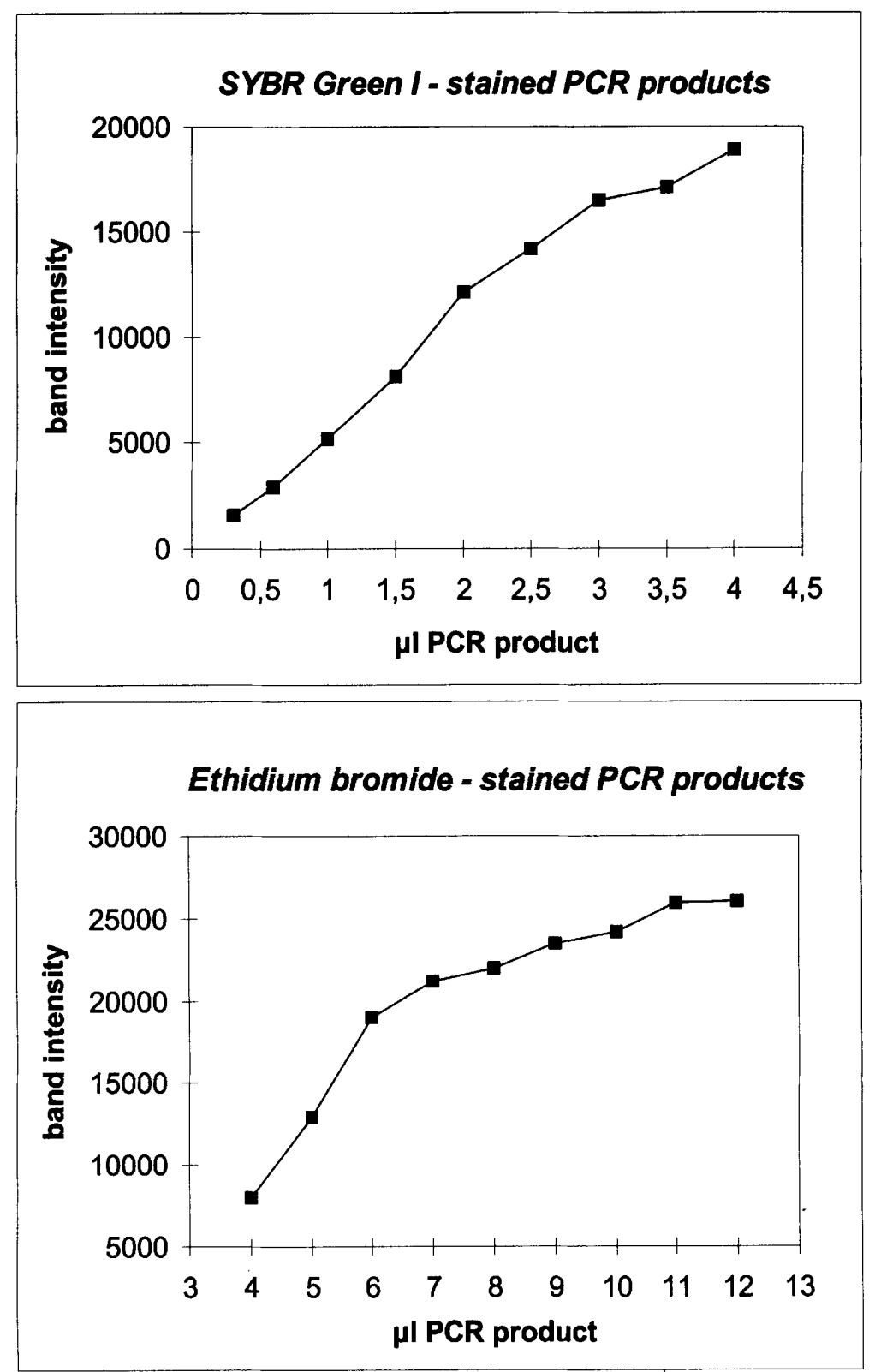

FIGURE 5 Relationship between fluorescence intensity and concentration of a 219-bp PCR product, stained with either SYBR Green I or ethidium bromide. Quantitative analysis was performed by densitometric scanning of the gels shown in Fig. 4, A and B, using a CCD Video Camera Imaging System (Vilber Lourmat, Marne la Vallee, France).

in $1 \times \mathrm{TAE}$ ] for $25 \mathrm{~min}$ or by performing electrophoresis on dye-containing gels, which were precast by diluting the dye into the gel solution just prior to pouring the gel $(1: 10,000$ dilution of the SYBR Green I stock reagent or $5 \mu \mathrm{g}$ ethidium bromide/ml). Ethidium bromidestained gels were excited using $302 \mathrm{~nm}$ transillumination, whereas SYBR Green I-stained gels were excited using $254 \mathrm{~nm}$ transillumination. Gels were photographed with Polaroid 557 film, using a yellow (for the SYBR Green I gels) or red (for the ethidium bromide gels) gelatin filter.

\section{RESULTS AND DISCUSSION}

The problem of heteroduplex formation, which was associated with the use of our internal RT-PCR standard, was avoided by decreasing PCR cycle numbers (Fig. 1B.) Figure 2 shows the correlation of heteroduplex formation and cycle number. The relative amount of heterodu- plexes decreased from $36 \%$ ( 35 cycles) to $2 \%$ ( 26 cycles). Because of these results, we decided to reduce the cycle number for the EGFR RT-PCR system to 25 . To prove that SYBR Green I stains heteroduplexes, the PCR cycle number had to be extended to 35. As shown in Figure 3A and B, SYBR Green I stained the heteroduplex band but with much lower efficiency than ethidium bromide did. In addition, heteroduplexes showed much higher reduction of electrophoretic mobility in SYBR Green I gels compared with ethidium bromide gels. Although SYBR Green I can be used to stain double-stranded DNA with higher sensitivity than ethidium bromide, heteroduplexes would not necessarily yield the same sensitivity staining. We may well have discovered an unusual characteristic of this stain. It is known that the fluorescence quantum yield and fluorescence enhancement of SYBR Green I/RNA complexes is less than that of SYBR Green I/DNA complexes. It is possible that SYBR Green I either binds poorly to heteroduplexes compared with homoduplexes or yields a poor fluorescence quantum yield (compared with that observed with RNA) upon such binding. The loss of sensitivity, which is associated with the reduction of cycle numbers, can easily be offset by SYBR Green I staining instead of ethidium bromide staining (Fig. 1A). The sensitivity of the RT-PCR procedure is such that as little as $0.2 \mathrm{fg}$ ( $\sim 1000$ molecules) of the competitor transcript can be detected easily by agarose gel electrophoresis combined with SYBR Green I staining (Fig. 4A). Quantitative analysis revealed a much better linear relationship between fluorescence intensity and amount of PCR product for SYBR Green gels as opposed to ethidium bromide gels (Fig. 5), as well as accurate quantitative results in PCR with SYBR Green I over ethidium bromide. Figure 6, $A$ and $B$ show an example of our quantitative EGFR analysis system: SYBR Green I was used to stain competitive RT-PCR products obtained by 25 PCR cycles (Fig. 6A). Quantitative analysis (Fig. 6B) of this gel demonstrated the quantitative power of SYBR Green I in determining gene expression by competitive RT-PCR. Taken together, SYBR Green I has proven to be an extremely useful reagent for qualitative as well as quantitative PCR applications where high sensitivity or reduction of PCR cycle numbers is required. 


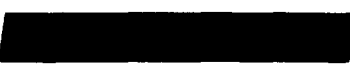

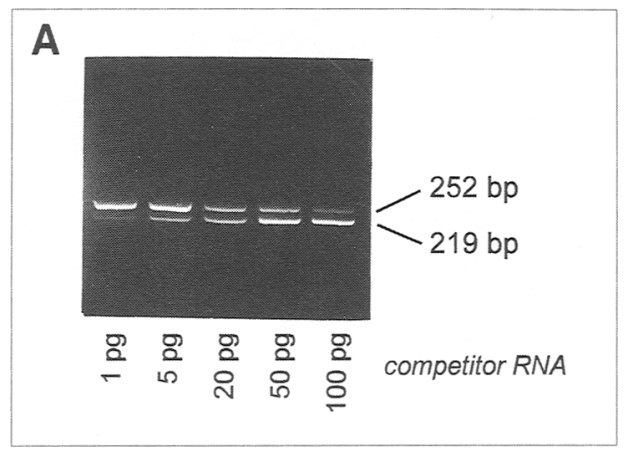

\section{B Competitive RT-PCR analysis}

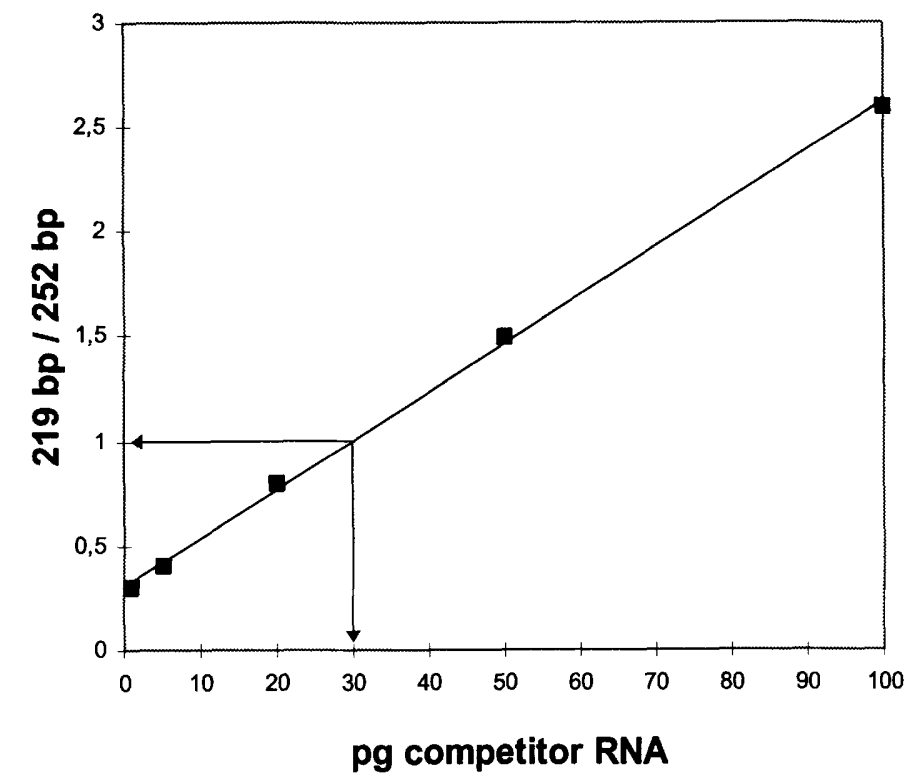

FIGURE $6(A)$ Competitive EGFR RT-PCR: $500 \mathrm{ng}$ total RNA, extracted from a breast cancer sample, was reverse transcribed and amplified in the presence of $1,5,20,50$, and $100 \mathrm{pg}$ of EGFR-competitor RNA. Staining of amplified products (10- $\mu$ l PCR products) was done by adding SYBR Green I to the agarose solution prior to pouring the gel. $(B)$ Linear plot of data obtained by densitometric scanning of $(A)$. Plotting of the concentration of EGFR-competitor RNA vs. the 219-bp/252-bp ratio, allows calculation of the concentration of EGFR-mRNA. At the theoretical equivalence point $(219 \mathrm{bp} / 252 \mathrm{bp}=1)$ the amount of EGFR-competitor RNA equals the amount of EGFR-mRNA present in the analyzed sample.

\section{ACKNOWLEDGMENTS}

This work was supported by the Fonds zur Förderung der wissenschaftlichen Forschung, project number P10032MED. We thank Elisabeth GharehbaghiSchnell and Sabine Eder for technical assistance.

\section{REFERENCES}

1. Arnheim, N. and H. Ehrlich. 1992. Polymerase chain reaction strategy. Annu. Rev. Biochem. 61: 131-156.
2. Wright, P.A. and R. Wynford-Thomas. 1990. The polymerase chain reaction: Miracle or mirage? A critical review of its uses and limitations in diagnosis and research. J. Pathol. 162: 99-117.

3. Becker-André, M. and K. Hahlbrock. 1989. Absolute mRNA quantification using the polymerase chain reaction (PCR). A novel approach by a PCR aided transcription titration assay. Nucleic Acids Res. 17: 94379446.

4. Gilliland, G.S., S. Perrin, K. Blanchard, and H.F. Bunn. 1990. Analysis of cytokine mRNA and DNA: Detection and quantifi- cation by competitive polymerase chain reaction. Proc. Natl. Acad. Sci. 87: 27252729.

5. Murphy, L.D., C.E. Herzog, J.B. Rudick, A.T. Fojo, and S.E. Bates. 1990. Use of the polymerase chain reaction in the quantitation of mdr-1 gene expression. Biochemistry 29: 10351-10356.

6. Wang, A.M., M.V. Doyle, and D.F. Mark. 1989. Quantitation of mRNA by the polymerase chain reaction. Proc. Natl. Acad. Sci. 86: 9719-9721.

7. Hsieh, C.-H. and J.D. Griffith. 1989. Deletions of bases in one strand of duplex DNA, in contrast to single-base mismatches, produce highly kinked molecules: Possible relevance to the folding of single-stranded nucleic acids. Proc. Natl. Acad. Sci. 86: 4833-4837.

8. Jensen, M.A. and N. Straus. 1993. Effect of PCR conditions on the formation of heteroduplex and single-stranded DNA products in the amplification of bacterial ribosomal DNA spacer regions. PCR Methods Applic. 3: 186-194.

9. Ruano, G. and K.K. Kidd. 1992. Modeling of heteroduplex formation during PCR from mixtures of DNA templates. $P C R$ Methods Applic. 2: 112-116.

10. Kury, F.D., C. Schneeberger, G. Sliutz, E. Kubista, H. Salzer, M. Medl, S. Leodolter, H. Swoboda, R. Zeillinger, and J. Spona. 1990. Determination of HER-2/neu amplification and expression in tumor tissue and cultured cells using a simple, phenol free method for nucleic acid isolation. Oncogene 5: 1403-1408.

11. Ullrich, A., L. Coussens, J.S. Hayflick, T.J. Dull, A. Gray, A.W. Tam, J. Lee, Y. Yarden, T.A. Libermann, J. Schlessinger, J. Downward, E.L. Mayes, N. Whittle, M.D. Waterfield, and P.H. Seeburg. 1984. Human epidermal growth factor receptor cDNA sequence and aberrant expression of the amplified gene in A431 epidermoid carcinoma cells. Nature 309: 418-425.

Received June 7, 1994; accepted in revised form December 19, 1994. 


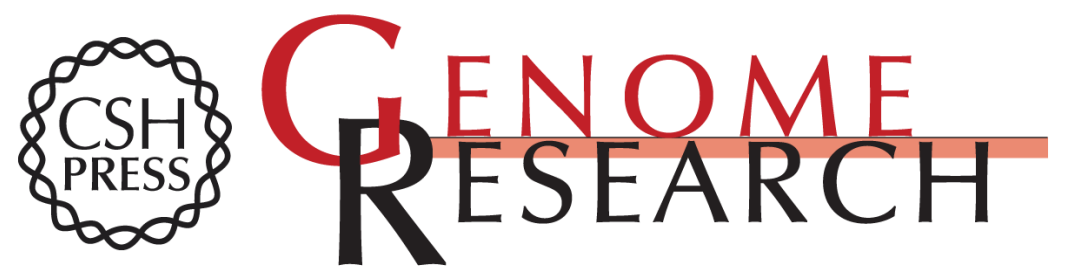

\section{Quantitative detection of reverse transcriptase-PCR products by means of a novel and sensitive DNA stain.}

C Schneeberger, P Speiser, F Kury, et al.

Genome Res. 1995 4: 234-238

References This article cites 11 articles, 2 of which can be accessed free at: http://genome.cshlp.org/content/4/4/234.full.html\#ref-list-1

License

Email Alerting

Receive free email alerts when new articles cite this article - sign up in the box at the Service top right corner of the article or click here.

\section{Affordable, Accurate Sequencing.}

To subscribe to Genome Research go to: https://genome.cshlp.org/subscriptions 